\title{
O ENREDAMENTO DAS OBRAS LITERÁRIAS JAPONESAS NO PRESENTE ${ }^{1}$
}

\section{Neide Hissae Nagae ${ }^{2}$}

Resumo: Fundamentando-nos na visão do estudioso Kato Shuichi $(2007 ; 2012)$ de que na cultura japonesa há uma tônica no agora=aqui e que mostra como esse aspecto se faz notório na composição das obras literárias japonesas em geral no tocante às escolhas linguísticas, e pretendemos, a partir desse apontamento, proceder a uma reflexão sobre a ênfase no presente na literatura japonesa. Para tanto, serão tomadas como exemplo algumas obras pertencentes a autores e épocas diversas, tecendo comentários a respeito de seus finais que deixam a impressão de uma interrupção que aponta para uma continuidade do enredo e que lembra o poema japonês waka quanto ao recurso estilístico conhecido como yoin.

Palavras-chave: Literatura Japonesa Moderna; tempo e espaço; presente.

Abstract: Based on the vision of the scholar Kato Shuichi (2007) that defends a focus in here = now in the Japanese culture and demonstrated how this characteristics appears in the linguistics options in the literature works that he analyses, this paper aims to do some reflections around the focus in the present time in the Japanese literature. Then, using works about different authors and different times, we intend to do commentaries about the final of some novels that creates an impression that they don't have a conclusion or that the novel to be continue same as the poem waka when it uses a stylistic recourse known as yoin.

Keywords: Modern Japanese Literature; time and space; present.

1 Este artigo é resultado de uma reflexão a respeito da ênfase no presente que temos observado nas obras literárias japonesas e que se mostrou fundamentada pela visão do tempo e espaço de Kato Shuichi (2007) presente na cultura japonesa. Parte dele foi utilizada em palestra realizada na Universidade de Brasília em 07 de outubro de 2011.

2 Docente da Área de Língua e Literatura Japonesa do Departamento de Letras Orientais, da Faculdade de Filosofia, Letras e Ciências Humanas da USP. 


\section{Introdução}

O conhecido recurso in media res ocorre no início de obras em prosa, em geral por meio de uma fala ou de um diálogo e proporciona a sensação de que a narrativa já se encontra em curso, sem nenhuma apresentação das personagens, ambientação ou contextualização temporal. Estas serão conhecidas ao longo da obra por meio de intervenções do narrador ou dos próprios personagens ao serem sumariadas ou descritas em flashbacks, por exemplo. Esses inícios constituem uma tentativa de aproximar o leitor do conteúdo narrado, como se ele presenciasse a cena naquele exato momento.

Do mesmo modo, os desfechos podem produzir efeito semelhante. Ao término da leitura de algumas obras, permanece a sensação de que ainda faltariam um ou mais capítulos para o final de seu enredo, reforçando a ideia de que a obra tende a efetuar um recorte no tempo e espaço cujo início e fim não são totalmente elucidados. Para tanto, fundamentar-nos-emos na ênfase no aqui=agora demonstrados por Kato $(2007$; 2012). para apresentar algumas obras literárias com as características mencionadas acima.

Não se pretende com isso, afirmar que os finais de obras sem desfechos são exclusividade das obras literárias japonesas, mas sim de observar a necessidade de refletir a respeito desse fenômeno recorrente na prosa japonesa. A propensão das obras japonesas para deixar em aberto o seu desfecho, gerando uma expectativa para com uma continuidade do assunto por parecer que ainda falta concluir o seu enredo, pode causar certo estranhamento ao leitor, mas por outro lado, possibilita-lhe dar asas à sua imaginação. Justifica-se essa reflexão, primeiro em função de uma proximidade desses desfechos com o recurso estilístico conhecido como yoin empregado nos poemas waka a fim de produzir um efeito de continuidade, justamente por meio da interrupção intencional causando um espaço a ser preenchido com uma reverberação daquilo que foi exposto no poema; do que poderia ser sentido ou pensado, ao deixar de expressar tudo na íntegra, transferindo para o interlocutor a apreensão de algo que poderia estar ali, conforme será apresentado mais adiante. Segundo, pela existência dos poemas-respostas kaeshi uta ou henka, cultivados desde os tempos antigos, os quais sinalizam para esses aspectos de continuidade tanto na poesia quanto na prosa e ao longo da produção japonesa.

Assim, para traçarmos um paralelo entre as obras dos dois gêneros literários, começamos por apresentar de modo sucinto a forte presença dos poemas na literatura japonesa. Em seguida, discorremos brevemente sobre os estudos de Kato acerca do foco no presente na língua e na literatura japonesa, procedendo à apresentação das obras modernas em prosa escolhidas para exemplificação de seus finais. Por fim, teceremos reflexões sobre esse fenômeno nas obras em prosa 
japonesas utilizando-nos de visões de estudiosos da literatura para demonstrar a ênfase no presente como uma das característica da cultura japonesa.

\section{Os poemas na literatura japonesa}

A presença de poemas é observada nas obras literárias desde os seus primórdios com as obras Kojiki (Registro de Fatos Antigos) de 702, e Nihonshoki (Crônicas do Japão) de 712. Conhecidos como kikikayô, cantigas e poemas do Registro e das Crônicas, são cerca de 200 poemas $^{3}$. Os poemas presentes nos nikki, - diários literários - podem constituir um diálogo entre as personagens que trocam poemas-cartas como ocorre com Kagerô nikki (Diário do Pirilampo) escrito por volta de 974 e Izumi Shikibu nikki (Diário da dama Izumi) de aproximadamente 1008. IENAGA (1982) enfatiza as origens de natureza popular (shominteki yôso) no desenvolvimento dos monogatari, - narrativas que ele aproxima das prosas de ficção ou romances, chamados no Japão de shôsetsu, - desde Taketori Monogatari, a Narrativa do apanhador de bambu, a mãe de todas as narrativas produzida por volta do final do século IX, e mostra que apesar da tentativa de fazer sobressair os aspectos da nobreza em Ochikubo monogatari (Narrativas do pavimento inferior) do final do século $\mathrm{X}$, o tema que envolve os maus tratos da madrasta para com a enteada não deixa de fazer parte das histórias transmitidas entre o povo. Ele comenta que o mesmo ocorre com as Narrativas de Genji, obra que traz, por exemplo, o caso da personagem feminina Tamakazura que irá alcançar projeção social depois de percorrer regiões afastadas da capital e à custa de muito sofrimento. Além dessas origens na camada popular, o estudioso salienta que assim como as demais narrativas, essa obra criada por Murasaki Shikibu é permeada por uma quantidade significativa de poemas, os quais teriam a importante função de desenvolver o enredo, apontando ainda, para o fato de que outra origem seriam os utamonogatari - narrativa mescladas por poemas, - que se desenvolveram a partir dos textos introdutórios denominados kotobagaki, que precediam o poema explicando as circunstâncias de sua elaboração:

\footnotetext{
"Obervando que na história dos monogatari obras como Ise monogatari e Yamato monogatari ${ }^{4}$ que reuniam histórias curtas em torno aos poemas waka aparecem juntamente com Taketori monogatari, é possível depreender que a arte narrativa
}

3 Britannica (2009) menciona 112 ou 113 poemas para Registro e 128 para as Crônicas, mas excluindo as repetições, considera que sejam aproximadamente 200.

4 Narrativas de Ise, produzida por volta de 913, possui 210 poemas e Narrativas de Yamato, datada de aproximadamente de 951 , possui 295 poemas. 
dos monogatari irá se desenvolver com o cruzamento entre as histórias do povo e as narrativas poéticas utamonogatari (IENAGA, 1982, p. 89 - tradução nossa).

Desse modo, os poemas não apenas contribuíram para o desenvolvimento das obras classificadas como monogatari como também constituem parte relevante indicando uma forma literária híbrida de prosa e poesia. Essa mistura é curiosa, mas natural se pensarmos que o Japão desenvolveu formas literárias distintas das produzidas na Europa e como é possível observar, com fronteiras muito tênues entre os dois gêneros.

Seguindo o desenvolvimento do panorama literário japonês é possível observar que a paz reinante em solo japonês após a unificação do país pela família Tokugawa, no século XVII, propiciará o desenvolvimento de uma classe citadina, gerando novos gostos e hábitos, com uma diversidade maior na produção literária. Surge o haikai desenvolvido a partir do desmembramento dos poemas encadeados que tinham por base a estrofe superior e inferior dos poemas waka iniciando-se pela estrofe inicial hokku; os livros ilustrados direcionados às mulheres e crianças; e narrativas sarcásticas e humorísticas, entre as de natureza mais sérias e moralizantes.

Assim, com exceção de obras como Trilha estreita ao confim (Oku no hosomichi) de 1702 de Matsuo Basho que é um diário poético de viagem, a presença dos poemas em obras de cunho narrativo parece tornar-se menos relevante em gêneros do período pré-moderno como ukiyozôshi e yomihon a exemplo de Kôshoku gonin onna de 1686 (Cinco mulheres apaixonadas) de Ihara Saikaku e Contos da chuva e da Lua (Ugetsu monogatari) de 1776, da autoria de Ueda Akinari.

\section{A ênfase no presente: aspectos linguísticos do japonês}

Kato $(2007 ; 2012)$ apresenta exemplos da tônica no presente nas obras literárias. Começando por demonstrar características da língua japonesa na seção que ele denomina de estilo das narrativas, empreende um passeio por trechos de obras famosas de diversos períodos da literatura japonesa, tanto as escritas em prosa quanto as em poesia e as ensaísticas.

Se nas Narrativas de Genji (Genji monogatari) do Século XI, o estudioso demonstra o uso de uma narração no presente em meio a várias outras no passado para dar ao leitor a impressão de que ele está diante da cena narrada, nas Narrativas do clã Taira (Heike monogatari) do século XII, mostra que esse efeito é maior devido à técnica de descrição do presente. O estudioso exemplifica com o uso de uma onomatopeia para descrever o momento em que uma personagem atira uma flecha para dizer que o som do arremesso transporta o leitor para aquele instante. Essa forma que Kato considera engenhosa, ele diz ser mantida no período 
Tokugawa como demonstra por meio de uma das obras de Contos da chuva e da lua em que "A capacidade notável de Ueda Akinari está em descrever o clímax da obra no espetáculo visto por uma terceira pessoa no presente." (KATO, 2012, p. 76). Mesmo no período Meiji (1868-1911) em que o Japão deixa o período clássico, ou seja, no início da chamada modernidade japonesa, Natsume Soseki (1867-1916) e Mori Ogai (1862-1922) são citados por meio de suas obras Sonhos de dez noites (Yume Jûya) de 1908 e Kanzan e Jittoku (Kanzan Jittoku) de 1916, respectivamente, para mostrar que essa estratégia de trazer uma dada situação para o presente dentro de uma narrativa sobre o passado, continuou a mesma.

Kato, por fim, assim conclui:

\begin{abstract}
"Se supusermos que a característica da cultura japonesa é a de não tentar distinguir apuradamente os tempos passado, presente e futuro, nossa tarefa do momento é confirmar que essas características aparecem no tempo verbal da língua japonesa, e que as características do tempo verbal da língua japonesa se refletem no estilo literário japonês que vai de Genji Monogatari até Ôgai e Sôseki”. (KATO, 2012, p. 83)
\end{abstract}

Kato (2007; 2012), assim, analisa nessas obras os efeitos de ordem linguística que trazem as cenas descritas para o presente, dando ao leitor a sensação de participar do evento narrado.

Recurso semelhante é observável no foco narrativo de $O$ país das neves de Kawabata Yasunari, em que o narrador em terceira pessoa do singular posiciona-se junto à personagem, ao usar principalmente o verbo kuru "vir" para descrever uma cena de deslocamento como ocorre, por exemplo, na parte inicial da obra quando o cenário descrito ocorre dentro de um trem:

No original em japonês:

$[\ldots]$

Mukôgawa no zaseki kara musume ga tattekite, Shimamura no mae no garasumado o otoshita. [...] (KAWABATA, Y. Yukiguni, 1956, p. 6)

E na tradução para o vernáculo:

Uma moça levantou-se do assento do outro lado do corredor e veio abrir a janela bem em frente a Shimamura. [...] (KAWABATA, Y. O país das neves, 2005, p. 9)

Nesse trecho, temos tattekite "levantar-se + vir", um tipo de locução verbal ou verbo composto que mostra o movimento da moça (musume) levantando-se de seu assento localizado do outro lado (mukôgawa no zaseki kara) do corredor daquele vagão, "vindo" e não "indo" na direção de Shimamura, o protagonista 
junto ao qual o narrador mostra-se posicionado no momento da descrição, e que causará ao leitor a impressão de presenciar a cena ${ }^{5}$.

Trata-se de uma forma eficaz para identificar o ponto de vista do narrador com o do protagonista, colocando a visão do leitor no mesmo ponto de vista dele, e essa característica da língua japonesa transforma-se em um recurso literário que produz um efeito de "presentificar" a cena descrita. A posição do narrador em uma obra escrita em terceira pessoa tende a fixar o seu ponto de vista na personagem (KOBAYASHI, 2009), e, no exemplo apontado em $O$ país das neves, em seu protagonista.

A partir de tais constatações e dos estudos de KATO (2007) sobre a questão da relevância dada ao agora=aqui, pudemos desenvolver uma hipótese de que as obras literárias japonesas independentemente de sua extensão poderiam apresentar uma tônica no presente, por meio de um enredo sem um desfecho. Por vezes um recorte, uma história que privilegia um fragmento com ênfase no transcurso, e por isso mesmo sem fim, que era algo já observado desde as nossas primeiras leituras das obras literárias japonesas no tocante ao enredo.

É o que ocorre com $O$ país das neves ao qual viajamos em contato com as surpresas que as descrições de Kawabata ainda marcadas pela corrente neo-sensorialista japonesa à qual pertenceu, propiciam aos nossos sentidos, ao nosso coração e à nossa mente. Uma obra que retrata o cotidiano inusitado de pessoas afastadas das grandes cidades, que vivem em meio a seus temores e desafios, sua beleza e suas dores. Os visitantes tentam reconfortar seus corações desgastados nesse universo de paisagens magníficas de fazerem perder o fôlego, de túneis escavados sob a neve para permitir a passagem das pessoas. E a vida nelas é tão rigorosa quanto o seu clima. As lembranças de tradições de um Japão em vias de extinção são vistas com nostalgia pelo protagonista, e Kawabata encarregou-se de perpetuá-las por meio de sua literatura. Os encontros e desencontros de Shimamura, Komako e Yoko chegam a uma situação periclitante diante das surpresas que a vida lhes oferece e sabemos que a obra chegou ao fim, porque as páginas do livro acabaram, mas não se sabe o desfecho dos destinos de cada um, os quais não está incluso no enredo.

Assim, além de $O$ país das neves, destacamos algumas obras em prosa sem uma preocupação com a análise da obra como um todo; apenas com o propósito de observar os seus finais que apresentam uma suspensão quanto ao seu desfecho,

5 Em Yukiguni (1956) original de O país das neves, que possui 183 páginas, é possível encontrar várias ocorrências como a exemplificada em cerca de 30 páginas e, ocasionalmente, mais de uma vez na mesma página. Ou seja, kuru, utilizado apenas para expressar deslocamento e exclusivamente na parte narrativa, desconsiderando-se suas ocorrências nos diálogos e com significados e usos outros como yurundekitari (começar a afrouxar); mottekuru (trazer). 
restando ao leitor apenas imaginá-lo, delineando possibilidades quanto à conclusão do enredo ou ao futuro das personagens. Nelas não se concretiza a definição de fim de Aristóteles (1997, p. 26): "é aquilo que, de per si e por natureza, vem após outra coisa, quer necessária, quer ordinariamente, mas após o quê não há nada mais". Obviamente, é possível continuar a história, mas a partir de uma nova etapa, e não como acontece na obra mencionada.

Foram escolhidas para este trabalho, portanto, obras encontradas em português e escritas até o século XX, a partir da época em que os comentários de Kato cessam com Ogai e Soseki, contemplando tanto as obras da dita literatura culta quanto a da popular. A saber: Rashômon (1915) de Akutagawa Ryunosuke; Trajetória em Noite Escura (1937) de Shiga Naoya; As Irmãs Makioka (1943) de Tanizaki Jun'ichiro; Pôr-do-Sol (1947) de Dazai Osamu; O templo do pavilhão dourado (1956) de Mishima Yukio; Mulher das Dunas (1962) de Abe Kobo; Chuva Negra (1965) de Ibuse Masuji; Norwegian Wood (1987) de Murakami Haruki e Miso Soup (1997) de Murakami Ryu.

Este levantamento não pretende esgotar e nem fechar o assunto a respeito dos finais das obras literárias japonesas, pois existem as que foram produzidas no mesmo período e que são criadas e estruturadas com um desfecho. O presente estudo pretende apenas apresentar as obras de forma mais geral e com uma preocupação de tentar não revelar os detalhes e as surpresas reservadas pelos seus autores nos últimos parágrafos, uma vez que necessita focar os seus finais.

Famosas por suas ambientações em uma época passada, as obras de Akutagawa Ryunosuke possuem uma estruturação elaborada, envolvendo o leitor em suas tramas psicológicas. Em Rashômon, ela é ambientada supostamente no portal principal da gloriosa capital Heian localizado no acesso à avenida central chamada Suzaku, e que se encontra em ruínas como toda a cidade. O portal possui um andar superior onde eram depositados cadáveres, e o protagonista sobe as escadas em busca de abrigo noturno e encontra uma luz. A vida ou a morte pode ser decidida em uma fração de segundos. Difícil distinguir entre o certo e o errado. A obra, em suma, revela um dos retratos universais do ser humano por meio de uma narrativa breve. Mas qual será o destino do protagonista? Difícil de divisar como o breu da noite.

Trajetória em noite escura foi escrita por Shiga Naoya em 1912 e interrompida a partir de 1921 por longos anos até finalmente ser concluída em 1937. É uma obra escrita em terceira pessoa, nos moldes de um romance de formação em que o protagonista Kensaku precisa passar por provações de ordem psicológica e emocional, enfrentando os revezes da vida que têm início na infância no seio familiar. Essa longa narrativa com um prefácio bem incomum e composta por quatro partes levou mais de duas décadas para ser concluída, mas o tempo da narrativa é de cerca de quatro anos. Foca na vida adulta de Kensaku, com um retrato interessante sobre 
as relações familiares; os confrontos e as amizades com seus colegas escritores; as experiências amorosas complicadas e as alegrias e sofrimentos na vida de casado. A dúvida que paira é quanto ao seu destino no final da obra. É como se o autor precisasse ter vivido mais e passado por diversas experiências para dar continuidade à escrita que apresenta pequenas pinceladas sobre a situação da sociedade japonesa em meio à narração da vida do protagonista também recheada de diálogos com obras de autores japoneses e estrangeiros. Mesmo assim, na última página resta a impressão de que o autor precisaria ainda de mais tempo para concluir a obra e de que ele está novamente a interrompê-la para retomá-la no futuro.

Tanizaki Jun'ichiro, continuando fiel ao tema da idolatria pela figura feminina, perseguida desde o início de sua carreira literária, cria em As irmãs Makioka a figura de Yukiko, uma moça que seria a representação da imagem de um Japão nostálgico de uma tradicional família comercial da região Oeste do Japão. Tsuruko e Sachiko, suas irmãs mais velhas, e Taeko, a mais nova também fazem parte da trama que envolve toda a família Makioka, cada qual em busca de satisfazer seus anseios e necessidades. Concluída em 1948, é uma obra que narra a busca por um marido ideal para a terceira das irmãs em meio à decadência dessa família e de um país em grandes transformações, de um avanço desenfreado rumo aos sonhos de conquista do continente chinês e que fará o Japão desembocar na guerra do Oceano Pacífico após o ataque a Pearl Harbor. O rumo da vida de cada uma das irmãs vai sendo descrito em meio a esse turbilhão, de modo tão inusitado quanto ao que o Japão irá tomar adentrando na Segunda Grande Guerra.

Pôr-do-Sol, da autoria de Dazai Osamu, publicada em 1947 é outra obra também ambientada nas consequências dessa guerra mundial para todo o povo japonês, mas que foca, em especial, os nobres decaídos na sociedade japonesa. Kazuko, sua mãe e o irmão Naoji, são um exemplo. As duas são mantidas por um tio enquanto seu irmão Naoji está nos campos de batalha, e a jovem também precisa enfrentar situações novas e adversas e trabalhar com serviços pesados para ajudar no sustento. As pressões são grandes tanto para os homens quanto para as mulheres sem os antigos privilégios, e Kazuko irá assumir uma paixão por um escritor casado e decadente, despontando como uma força feminina vigorosa a deixar os leitores curiosos.

Outra obra que desperta esse sentimento é O pavilhão dourado (1956) de Mishima Yukio. Tendo por cenário uma das obras representativas da arquitetura japonesa, é baseada em um incêndio que ocorreu no templo em 1950. Filho de um sacerdote budista que adorava o Templo do Pavilhão Dourado, o protagonista Mizoguchi acaba sendo acolhido pelo prior desse templo e virando aprendiz de monge após a morte do pai. Nele recebe o final da guerra e as mudanças dos tempos e cedo aprende a desprezar o prior. Curiosamente, é indicado por esse velho mestre a estudar na Universidade Otani que lhe garantiria ser o seu sucessor e 
futuro dirigente do templo. Possuidor de sentimentos sombrios, vive dividido entre o bem e o mal e descreve a si mesmo como solitário, infeliz, até que a ideia de transformar o templo em cinzas começa a mover o seu ser.

Chuva negra de Ibuse Masuji foi publicada no Japão em 1965. É uma obra que retrata a situação dos habitantes com o lançamento da bomba atômica em Hiroshima, registrando quase de modo documental os acontecimentos antes, durante e após o que é chamado de clarão. A obra nos põe em contato com cenas que buscam relatar os horrores da guerra, e parte da visão sobre esses acontecimentos centrada no relatório que Shigematsu escreve a partir do diário de Yasuko, sua sobrinha, para comprovar que ela não sofrera diretamente os efeitos da radiação e que, portanto, estaria apta para o casamento. O protagonista é atormentado não apenas pela situação geral, mas também sobre o destino da jovem que está sob sua responsabilidade. Ele tenta ganhar força com o exemplo das enguias que se desenvolvem mesmo depois da queda da bomba atômica em Hiroshima e deposita esperanças no poder de recuperação da natureza. O surgimento de um arco-íris será o símbolo de uma promessa de um final feliz para a sua sobrinha, mas tão incerto quanto o desfecho de Kazuko de Pôr-do-Sol.

O mesmo impasse é encontrado em Mulher das dunas produzida em 1962 por Abe Kobo. A obra desse autor surrealista, apresenta uma situação extrema de clausura e dominação, uma armadilha de um não se sabe o quê, próprio do ser humano. O protagonista é um entomólogo que, inesperadamente, entra em um mundo arenoso, desesperador e planeja a sua fuga o tempo todo, enquanto tenta sobreviver nesse mundo à espera do momento de libertação.

Norwegian Wood, a obra que deu notoriedade a Murakami Haruki em 1987 vai nos lançar, juntamente com o protagonista, para uma história romântica de jovens iniciando suas experiências amorosas e sexuais, descobrindo-se a si mesmo e aos outros. Os sentimentos complexos de uma juventude em formação e até os sofrimentos mais profundos diante de fatos trágicos que eles enfrentam parecem suavizados com o toque de delicadeza da escrita do autor. E, da mesma forma que o protagonista, ficaremos perdidos no desfecho que assinala a separação com as garotas que lhe foram importantes na vida e o início de uma nova etapa com a pessoa que afirma amar.

Em direção oposta, Murakami Ryu usa de uma escrita chocante que chega a ser agressiva para exibir facetas da vida noturna do Japão contemporâneo em Miso Soup escrito em 1997. Mediante um personagem estranho e perigoso criado pelos próprios problemas do mundo capitalista, revela a cruel realidade de homens e mulheres que vivem na solidão, cercados pela violência. O protagonista que se envolve com esse personagem enigmático e imprevisível sente-se ameaçado, mas angaria a sua simpatia, e se separam. Seu final, contudo, segue na linha de um romance de mistérios encaminhada pela cena final. 
Essas obras de diferentes épocas, de naturezas variadas, de autores pertencentes a correntes estéticas distintas, obviamente apresentam muitas formas inusitadas de finalizações. Apesar de todas essas diferenças, elas possuem em comum uma indefinição quanto ao desfecho e podem frustrar a expectativa de um final que trace um desenlace nos moldes aristotélicos. Por isso, no final da obra permanece uma sensação de que a história continua e, mais do que isso, uma curiosidade sobre os motivos dessa escolha pela indefinição.

Pensando-se no efeito que os poemas japoneses apresentam no sentido de lançar um fato, uma imagem, uma ideia, que irão tocar o leitor fazendo com que a sensação causada pelo poema tenha continuidade, faça-a reverberar em seu sentimento, é possível supor que esses finais inacabados da prosa japonesa apontem para uma provocação que é a de insinuar a pequenez do ser humano. Muito mais que um convite a concluir a narrativa ou dar-lhe continuidade.

NAKAMURA (1991) entende que toda obra literária tem um destinatário e que é possível dar ao leitor, a impressão de fazer parte do mundo ficcional da obra, inserindo-o numa cena ou ação logo no seu início recorrendo à técnica de média res, ou ao que ele chama em japonês de mubôtô. Apoiando-se no estudo realizado por Tokieda Makoto publicado em 1960, ele apresenta sucintamente os cinco tipos de início de obras literárias, defendidos pelo linguista, que apresenta um outro tipo que não pertence a nenhum dos cinco. Ou seja, aqueles que começam sem a intermediação do autor para que se apresente as personagens ou os acontecimentos diretamente ao leitor e que pode ser encontrado na prosa moderna japonesa. Começa com o exemplo de Morokkogawa no hon (Livro de couro marroquino) de Tochiori Kumiko escrito em 1975 e nele se detém para mostrar que o seu início é peculiar, e segue com Gubijinsô (Gubijinsô) escrito em 1907 por Natsume Soseki; As irmãs Makioka de Tanizaki; Ha (Folha) de 1934 de Osamu Dazai; Ainekoshô (Excertos sobre meu amado gato) escrito em 1920 por Muro Saisei; Kura no naka (Dentro do depósito) de 1918 de Uno Koji, como exemplos próximos que introduzem o leitor no universo da obra.

Apesar de explorar os recursos utilizados no início da obra com uma preocupação voltada para o lado da recepção, o estudioso pouco explora os finais das obras. Menciona que existem diversos tipos de desfechos. Entre os exemplos apresentados por NAKAMURA (1991, p. 85) quanto às formas de finalização da obra, interessariam para esta análise a forma mencionada pelo estudioso como "um indício de desenvolvimento de um novo assunto" (atarashii hanashi no tenkai o anji suru) para o final de Seibee to hyôtan (Seibee e as cabaças) de 1913 do escritor Shiga Naoya. Ao seu final, encontramos o garoto compenetrado na pintura depois de desfazer-se das cabaças que criaram o descontentamento de seu pai, e o narrador antevendo que ao término da tela Seibee já terá "curado" as feridas de seu pequeno coração, mas gerando incômodo ao pai devido a esse novo interesse. 
É possível pensar em influências resultantes do eco que os poemas japoneses produzem nos ficcionistas, principalmente quando se leva em consideração a mencionada relevância dos poemas na literatura japonesa e na formação intelectual e sentimental dos japoneses, como se pode observar desde a "Introdução em kana" de Kino Tsurayuki na primeira antologia oficial de poemas datada do início do século $\mathrm{XI}$, que mostra que os poemas são palavras manifestadas pelo sentimento por meio de uma forma, ou seja, a famosa tríade kokoro to kotoba to sugata: "coração, palavra e figura" (OKADA, 1974). Em se tratando dos poemas waka e haikai é observável o foco no momento da observação, da apreensão do fenômeno e do sentimento em que eles foram compostos como se fossem uma fotografia a registrar aquele instante. Não se compõe um poema de inverno estando na primavera. A tônica é o presente. No sentimento gerado pela apreensão dos sentidos do que está ali sendo vivido, presenciado. E esse flash é valioso porque único; o instante seguinte já não é o mesmo. A brevidade do poema tenta acompanhar o momento único que ele retrata. Contudo, os poemas transmitem uma sensação de completude, apesar de lançarem uma reflexão ao leitor e insinuarem uma continuidade por meio do recurso conhecido como yoin ou yojô, deixando algo no ar. Pois o encantamento do poema está justamente em não terminar de descrever tudo ou de expressar toda a emoção (OKADA, 1974).

Umberto Eco (2003), por sua vez, aponta que uma das funções principais da literatura é a educação ao Fado e à morte, ou seja, que é impossível mudar o final, o destino das personagens literárias. Os hipertextos igualmente apresentados pelo estudioso como capazes de hoje em dia oferecer ao leitor a possibilidade de participar da narrativa mudando a história que os livros consagraram como imodificáveis, assemelham-se muito, pelo menos no seu modo de finalização, às obras japonesas que apresentamos.

Retomando Kato $(2007 ; 2012)$, a tônica no presente é expressa por meio de dois adágios populares que são "kako wa mizu ni nagasu", ou seja, "deixar a água levar o passado", que corresponderia ao conhecido entre nós como "enterrar o passado", e "ashita wa ashita no kaze ga fuku." Em suma, "amanhã, outros ventos soprarão." Indicando de certo modo que "O futuro a Deus pertence" e nesse sentido contrariando Eco (2003) que se apoia em Deus, ou no fado e nas leis inexoráveis da vida para dizer que além de nos mostrar a impossibilidade de mudar as grandes histórias, elas nos ensinam a morrer.

\section{Considerações finais}

As obras escolhidas para mostrar a falta de desfecho das obras literárias japonesas por uma ênfase no presente, como uma reflexão sobre o estudo feito por Kato Shuichi no tocante ao recurso de "presentificação", pertencem a autores 
e a épocas distintas, e diferente delas muitas possuem um final. Por isso, sem dúvida alguma, é necessária uma análise mais detida com a apresentação textual de seus finais sem a preocupação que se teve, nesta oportunidade, em não revelar integralmente o final de cada obra para não tirar o prazer da leitura das mesmas.

Este estudo, assim, é parte de uma reflexão sobre essas características detectadas em algumas obras como as aqui citadas, mas que ainda necessita de uma pesquisa acurada com uma quantidade maior de obras e autores.

A partir dele, contudo, pudemos avançar alguns passos em novas constatações. Os desfechos de obras trágicas como Os miseráveis, Guerra e paz, Moby Dick, Madame Bovary ou Chapeuzinho Vermelho de Perrault não terminam com finais felizes como seria do agrado de muitos leitores, como diz Eco (2003), e se para ele "a trágica grandeza daquelas páginas de Hugo está no fato de que (além dos nossos desejos) as coisas acontecem como acontecem, a beleza de Guerra e $p a z$ é que a agonia do príncipe André se conclui com a morte, por mais que nos desagrade." (ECO, 2003, p. 20); que "A verdadeira lição de Moby Dick é que a Baleia vai para onde quer." (ECO, 2003, p. 20) ou que "podemos nos comover com a sorte de Emma Bovary" (ECO, 2003, p. 17), porque esses contos imodificáveis possuem a função de "nos fazer tocar com os dedos a impossibilidade de mudá-lo. E assim fazendo, qualquer que seja a história que estejam contando, contam também as nossas e por isso nós os lemos e os amamos" (ECO, 2003, p. 21). As obras japonesas não deixam de ensinar o mesmo, mas em geral, não com um desfecho imutável como diz o estudioso italiano.

Essa visão de Umberto Eco talvez explique a surpresa do leitor quando ele chega ao final das páginas do livro de obras japonesas como as aqui apresentadas e não encontra um desfecho, como se tivesse que ir em busca de um segundo volume que dará continuidade ao enredo.

No entanto, se seguirmos a linha de pensamento de Eco (2003) que comenta sobre a criação livre que o hipertexto trouxe com a participação coletiva em uma história, como ocorre na internet há algum tempo, e que questiona porque não se fazer o mesmo com as grandes histórias, por meio de um programa, veremos com igual surpresa, que aquelas obras japonesas já proporcionariam isso. Mesmo no formato de livro impresso, elas propiciam a liberdade de criação que a narrativa em hipertexto permitiria, pelo menos no que diz respeito aos seus desfechos dentro da imaginação de cada leitor. É como se naquelas obras os autores não falassem tudo que tivessem a dizer, tal como nos poemas, deixando que o conteúdo desenvolvido por ele em sua obra causasse efeitos com infinitas possibilidades.

Por que? Conforme já mencionado, Eco (2003) enxerga nos contos terminados da literatura europeia uma função educativa para o que ele chama de Fado e para a morte. E as obras japonesas? Como diz Kato (2007; 2012), por meio do budismo, acredita-se numa vida após a morte, no higan que estaria na outra mar- 
gem do rio que a alma atravessa quando desencarna, dita como a verdadeira e não a transitória, que é a vida no mundo "terreno", mas o que se valoriza é o shigan, o mundo da margem do lado de cá. Nessa linha de pensamento, o presente, o aqui e o agora é o que importa, é o que temos de certo, melhor deixar em aberto. As obras "já feitas" (ECO, 2003, p. 23) não são Ukigumo (Nuvens Flutuantes) escrita por volta de 1888 por Futabatei Shimei ou Meian (Claridade e Escuridão) de 1917, de autoria de Natsume Soseki, as quais mesmo inacabadas ficaram famosas e convidam o leitor a saboreá-la imaginando seu desfecho e incitam-no a continuar a escrita da obra a partir de sua interpretação. Presume-se igualmente, que a falta de ação encontrada na prosa japonesa seja reforçada por esse congelamento num tempo-espaço no qual predomina o presente.

\section{BIBLIOGRAFIA}

ABE, Kobo. Mulher das Dunas (1962). Tradução de Ernesto Yoshida. São Paulo: Aliança Cultural Brasil-Japão, 1995. 198 pp.

AKUTAGAWA, Ryunosuke. Rashômon (1915). In: . Rashômon e outras histórias. Tradução de Madalena Natsuko Hashimoto e Junko Ota, São Paulo: Paulicéia, 1992. $166 \mathrm{pp}$.

IBUSE, Masuji. Chuva Negra (1965). Tradução de Jefferson Teixeira. São Paulo: Estação Liberdade, 2011. 328 pp.

ARISTÓTELES. "Poética”. In: ARISTÓTELES, HORÁRIO, LONGINO. A poética clássica. Introdução de Roberto de Oliveira Brandão e tradução de Jaime Bruna. 7a . ed. São Paulo: Cultrix, 1997, p. 17-52.

DAZAI, Osamu. Pôr-do-Sol (1947). Tradução de Antonio Nojiri, São Paulo: Hamburg, 1974.

ECO, Umberto. Sobre a literatura. Tradução de Eliana Aguiar. Rio de Janeiro: Editora Record, 2003. 305 pp.

IKEGAMI, Yoshihiko. "Shukanteki haakutowa nanika." (Apreender por um ponto de vista subjetivo). In: Gekkan GENGO Tokushû ima to koko no gengogaku, Kotoba no shukansei o motomete. (Revista Mensal GENGO Edição especial: a linguística do aqui e do agora - em busca do ponto de vista subjetivo da língua). V. 35 N. 5. Tokyo: Taishûkan Shoten, 2006. p. 20-27.

KATO, Shuichi Nihon bunka ni okeru jikan to kukan (Tempo e o espaço na cultura japonesa). Tóquio: Iwanami Shoten, 2007. 280 pp.

Tempo e espaço na cultura japonesa (2007). Tradução de Neide Nagae e Fernando Chamas. São Paulo: Estação Liberdade, 2012. 280 pp.

Nihon Bungakushi Josetsu jō. (Compêndio da História da Literatura Japonesa I). Tóquio, Chikumashobō, 1975 (jō). 304 pp. 
A History of Japanese Literature 1 - The First Thousand Years. Translated by David Chibbet, Foreword by Ronald Dore. Tokyo, New York, London, Kodansha International, 1981. $319 \mathrm{pp}$.

KAWABATA, Yasunari. País das Neves (1935). Tradução de Neide Nagae. São Paulo: Estação Liberdade, 2005. 160 pp.

. A casa das belas adormecidas (1962). Tradução de Meiko Shimon. São Paulo: Estação Liberdade, 2004. 128 pp.

KOBAYASHI, Shuichi. Nihon no kôdo - nihonteki naru mono towa nanika ( $\mathrm{O}$ código do Japão - o que é algo japonês). Tokyo, Misuzu Shobô, 2009. 227 pp.

MISHIMA, Yukio. O pavilhão dourado (1956). Tradução de Shintaro Hayashi. São Paulo: Companhia das Letras, 2010. 283 pp.

MURAKAMI, Haruki. Norwegian Wood (1987). Tradução de Jefferson Teixeira. Rio de Janeiro: Objetiva, 2008. 359 pp.

MURAKAMI, Ryu. Miso Soup (1997). Tradução de Jefferson Teixeira. São Paulo: Companhia das Letras, 2005. 214 pp.

NAKAMURA, Akira. Nihongo no Retorikku. (Retórica da Língua Japonesa). Tokyo: Iwanami Shoten, 1991. $421 \mathrm{pp}$.

OKADA, Seiichi. Nihon Tankaron. (Teoria do poema tanka do Japão). Tokyo: Kyoikushuppan senta, 1974. $302 \mathrm{pp}$.

OKUNO, Takeo. Nihon bungakushi: kindai kara gendai e (História da Literatura Japonesa: da era pré-moderna à moderna) 29a . ed. Tokyo: Chuo Koron, 1992. 260 pp. Chuko Shinsho 212.

SHIGA, Naoya. Trajetória em Noite Escura (1937). Tradução de Neide Nagae. São Paulo: Ateliê Editorial, 2012. 368 pp.

TANIZAKI, Jun'ichiro. As Irmãs Makioka (1943). Tradução de Leiko Gotoda; Eliza Tashiro; Kanami Hirai e Neide Nagae. São Paulo: Estação Liberdade, 2005. 744 pp. 